\title{
Solute contaminant transport in variably saturated dual- porosityl dual permeability chalk: field tracer experiments and modelling
}

\author{
$\underline{\text { S. Brouyère }}$ \\ Hydrogeology and Environmental Geology, Dept of Georesources, Geotechnologies and \\ Building Materials (GeomaC), University of Liège - Belgium
}

Corresponding author: Building B52/3, 4000 Sart Tilman, Belgium

Tel: +32.43662377 - Fax: +32.43669520 - e-mail: Serge.Brouyere@ulg.ac.bet

\begin{abstract}
A detailed field investigation was performed for studying groundwater recharge processes and solute downward migration mechanisms prevailing in the unsaturated zone overlying a chalk aquifer in Belgium. Various laboratory and field experiments were performed, among others tracer experiments in the unsaturated zone. From the experiments performed in the variably saturated chalk, it appears that the migration and retardation of solutes is strongly influenced by recharge conditions. Under intense injection conditions, solutes migrated at high speed along the partially saturated fissures, reaching the saturated zone in a few hours. At the same time, they were temporarily retarded in the almost immobile water located in the chalk matrix. Under normal recharge conditions, fissures were inactive and solutes migrated slowly through the chalk matrix, taking about one year to reach the water table. The tracer experiments performed in the chalk were modelled using the finite element flow and transport simulator SUFT3D. The mathematical representation of the unsaturated properties of the fissured chalk is based on a new modified van Genuchten - Mualem relationship that takes into account the dual-porosity characteristics of the rock. For modelling the transport of the tracers, an adapted first-order transfer, dual-porosity model is used, based on a dynamic partitioning of water between effective and immobile water porosity according to the water saturation of the chalk. Conclusions are drawn in terms of recharge mechanisms and vulnerability of the chalk to pollutions occurring at the land surface.
\end{abstract}

\section{Keywords}

Dual porosity; dual permeability; chalk; unsaturated zone; transport; tracer

\section{Introduction}

The Hesbaye aquifer is located in the Senonian chalk formations of the Geer basin in the eastern part of Belgium. Since 1960, nitrate concentrations have risen annually at a rate ranging from $0.1 \mathrm{mg} / \mathrm{l}$ (as $\mathrm{NO}_{3}{ }^{-}$) in the semi-confined to $1 \mathrm{mg} / \mathrm{l}$ in the unconfined part of the aquifer. Presently, the mean 
concentration is around $35 \mathrm{mg} / \mathrm{l}$. To have a better knowledge and understanding of groundwater recharge mechanisms and transport processes in the unsaturated zone of the Hesbaye aquifer, an experimental study was performed, funded by the Walloon Ministry of Natural Resources and Environment. The experimental site is located at Bovenistier in the Hesbaye region. From top to bottom, the substratum is made of quaternary loess of variable thickness (up to $20 \mathrm{~m}$ ), locally several meters of tertiary sand deposits, a layer of flint conglomerates (maximum $10 \mathrm{~m}$ ), up to $70 \mathrm{~m}$ of Senonian chalk and several meters of smectite clay. Six boreholes were drilled. A central well (PC) was drilled down to the aquifer bottom $(50 \mathrm{~m})$. An observation well (Pz CS) was drilled and screened in the saturated zone $(34 \mathrm{~m})$. Four subsequent wells were drilled and screened in the unsaturated zone: Pz CNS in the unsaturated chalk (19.2 m), Pz CGL in the flint conglomerate (15.8 m) and Pz LB (9.4 $\mathrm{m})$ and LS (5.8 $\mathrm{m})$ in the loess formations. For each borehole, core drilling was first performed to take undisturbed samples used for performing laboratory experiments such as hydraulic conductivity measurements, texture and density analyses, retention curves measurements and pesticides and nitrate analyses. In the field, well logging (neutron, gamma-gamma and gamma ray) was performed in each well. Pumping tests were performed in the boreholes screened in the saturated zone and infiltration tests in the boreholes screened in the unsaturated zone. Tracer experiments were performed in both the saturated and the unsaturated zone. Details about the experiments can be found in Brouyère et al. (2004).

\section{Tracer experiments performed in the variably saturated chalk}

Two tracer tests were performed in the saturated zone, under radially converging flow conditions, between Pz CS and the central well (tracing distance: $6 \mathrm{~m}$ ). For the first injection the pumping rate at the central well was $1.2 \mathrm{~m}^{3} / \mathrm{h}$, for the second, $6.0 \mathrm{~m}^{3} / \mathrm{h}$. The breakthrough curves highlighted the very fast transit of tracers in the saturated zone, mostly along fissures, with a strong asymmetry and tail that reflected tracer dispersion and retardation in the immobile water located in the chalk matrix (results not shown). Tracers were also injected in Pz CNS screened in the unsaturated chalk. During the two years of monitoring, pumping was maintained almost permanently at the central well (3.2 to 6 $\mathrm{m}^{3} / \mathrm{h}$ ). During the period of the experiments, the thickness of unsaturated chalk was progressively reduced from 11 to $3 \mathrm{~m}$ because of a rise of groundwater levels. A first injection (potassium chloride $\mathrm{KCl})$ was performed under artificial recharge conditions created by adding water at a constant rate $\left(\sim 0.1 \mathrm{~m}^{3} / \mathrm{h}\right)$. This led to enhanced hydraulic gradient between the injection point and the aquifer and to a higher degree of saturation in the unsaturated chalk. A second tracer injection (potassium iodide KI) was performed without addition of water. This configuration better reflects actual seepage conditions in the unsaturated chalk. In the first case, the tracer was detected $5 \mathrm{~h} 15 \mathrm{~min}$ after injection, the maximum concentration being reached $11 \mathrm{~h} 30 \mathrm{~min}$ after injection (Fig. 1a). In the second case, transfer times were very different: the tracer was detected only after 340 days while, after 700 days (end of the monitoring campaign), the peak was still not reached even if concentrations seemed to stabilize (Fig. 1b).

To explain the strong contrast in terms of travel times (about three orders of magnitude), the dual porosity - dual permeability of the chalk has to be invoked. The chalk matrix is characterised by a high porosity and a low hydraulic conductivity at saturation. At Bovenistier, laboratory experiments performed on chalk matrix samples gave a matrix porosity ranging from 38 to $51 \%$, and a saturated hydraulic conductivity of $1.3 \times 10^{-8} \mathrm{~m} / \mathrm{s}$. It is made up of a large number of pores having dimensions of the order of $1 \mu \mathrm{m}$, in which capillary forces are very high. As a direct consequence, the matrix remains close to saturation and water is almost immobile. On the contrary, the porosity associated with the fissures is very low but their contribution to the saturated hydraulic conductivity of the rock is predominant. Here, pumping tests and infiltration tests show similar orders of magnitudes for the hydraulic conductivity of the fissured chalk $\left(10^{-5}-10^{-4} \mathrm{~m} / \mathrm{s}\right)$. Fissures are characterized by larger 
openings and capillary forces are not so developed. Under natural recharge conditions, they are most often empty and inactive in the unsaturated zone. The average velocity of downward migration of water and solutes in the unsaturated chalk is very low, governed by the low hydraulic conductivity and the large porosity of the matrix. During periods of intense water recharge, it may occur that the matrix becomes fully saturated. The excess of water is free to infiltrate through the fissure network with a quick increase of the chalk hydraulic conductivity. Water then flows mostly through the fissure network, the role of the matrix being limited to the storage and release of water and solutes. Under such conditions, any contaminant present in the infiltrating water is able to reach very quickly the water table by fast downward migration through the fissure network.
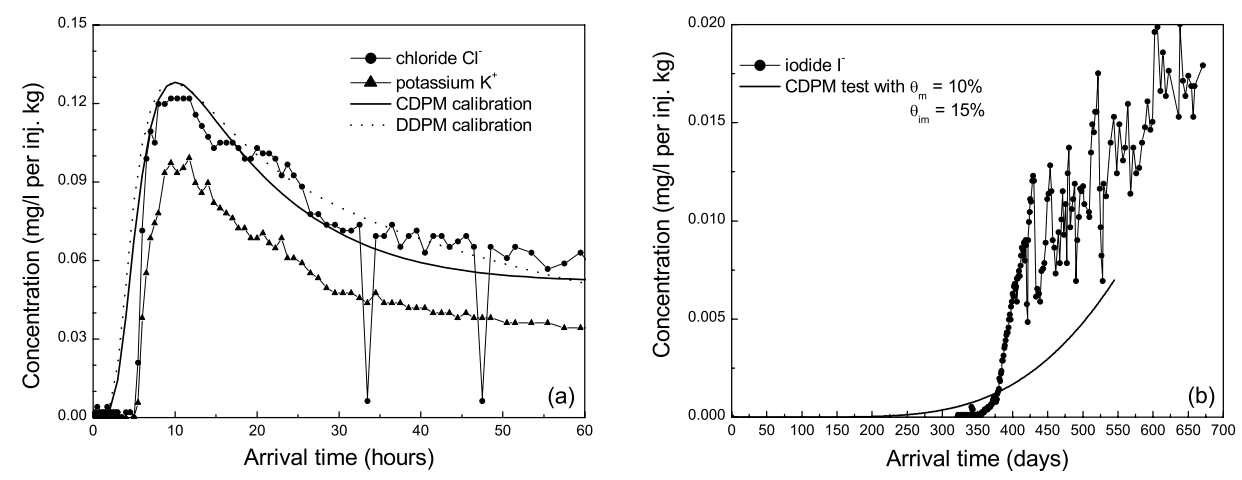

Fig. 1 - Breakthrough curves obtained for the tracer experiments performed in the unsaturated chalk and modelled using the SUFT3D (see section 4 for details).

\section{Mathematical model}

To transcribe mathematically the conceptual model presented here above, Brouyère (2001) developed an approach that relies on two main concepts. The unsaturated properties of the chalk are modelled using a modified van Genuchten relationship that accounts for the bimodal porosity of the rock. The retention curve of the chalk is modelled using the combination of two van Genuchten relationships, one defined for the matrix, one for the fissures.
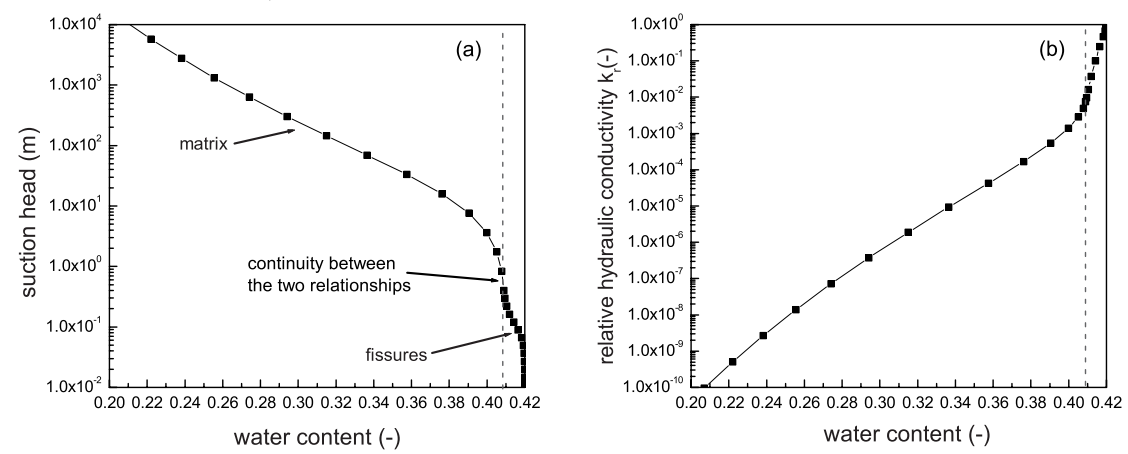

Fig. 2 - Retention curve (a) and hydraulic conductivity curve (b) developed for the fissured chalk. 
This model differs from that of Ross and Smettem (1993) or Durner (1994) by the fact that it forces a continuously derivable transition between the relations that describe the matrix and the fissure component respectively (Fig. 2a). Thanks to that, it is possible to derive analytically the hydraulic conductivity curve from the retention curve for the whole range of water contents (Fig. 2b), using the model of Mualem (1976). The hydraulic conductivity curve shows the expected evolution with water content or suction head. For a small suction applied, fissures desaturate and the hydraulic conductivity of the chalk rock drops by several orders of magnitude.

The dual-porosity first order transfer model is a very convenient model to compute contaminant transport and retardation in fissured rocks (e.g. Brouyère et al. 2000). This model introduces two parameters in the calibration process: the dual porosity $\theta_{i m}$ (no units) and a first order transfer coefficient $\alpha\left(\mathrm{T}^{-1}\right)$. In its original form, the porosity associated with the immobile water is assumed constant. However, when the rock mass desaturates, its hydraulic conductivity is reduced. Water located in the dual porosity and initially considered as immobile becomes the only vector of mobility of contaminants. In transient variably saturated groundwater flow conditions, the model has to be adapted by distributing dynamically water between the mobile and the immobile phases, depending of the saturation degree. Zurmülh and Durner (1996) suggest considering a constant ratio between the immobile water porosity and the total water content $c_{\text {part }}=\theta_{\text {im }} / \theta$ or distributing the water according to the ratio of intrinsic hydraulic conductivity values associated with the immobile water and the total water content $c_{\text {part }}=k_{r}\left(\theta_{i m}\right) / k_{r}(\theta)$

(a)

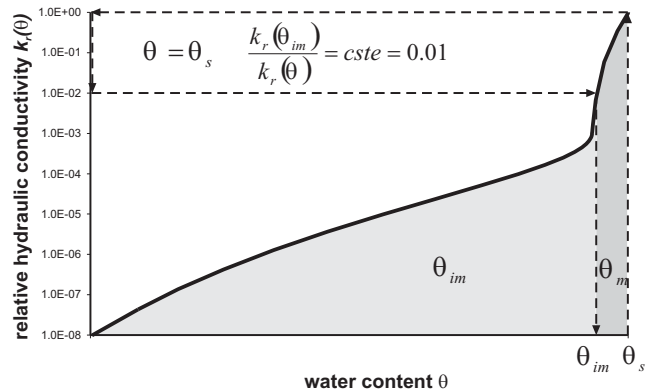

(b)

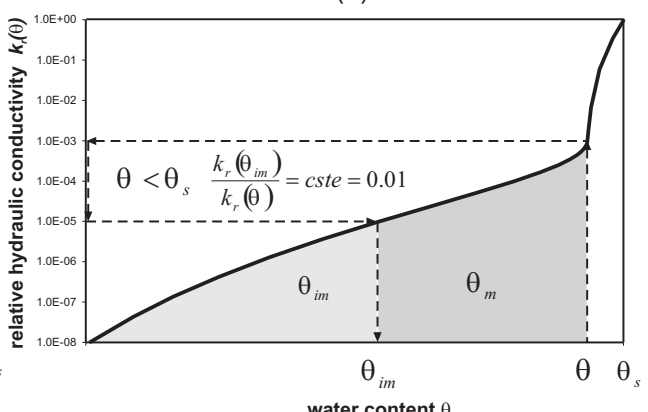

Fig. 3 - Dynamic partitioning of the water content between the mobile and the immobile water according to the saturation degree of the chalk rock: (a) matrix and fissures are saturated with water, (b) fissures are empty and the matrix is partially saturated.

Figure 3 illustrates this concept considering a partitioning coefficient of 0.01 . At saturation, the effective porosity is small, associated with the fissures, and the dual-porosity is important, associated with the matrix (Fig. 3a). When fissures desaturate, the effective porosity becomes larger, associated with a part of the water in the matrix, and the dual porosity is strongly reduced (Fig. 3b). This model was implemented in the SUFT3D finite element code (Brouyère 2001).

\section{Modelling results}

The two tracer experiments performed in the saturated chalk, between Pz CS and the central well, were used to calibrate hydrodispersive parameters in the saturated zone (Table 1). The calibrated effective porosity is low, typical of the porosity associated to fissures in the chalk. The first-order transfer coefficient is in a good agreement with values found for the fissured chalk in the Hesbaye aquifer. The immobile water porosity is relatively low. However, the tracers were injected very close 
from the recovery well and it is likely that a part of the immobile water did not participate to the retardation process. The tracer experiment performed in the unsaturated chalk under intense injection conditions was modelled assuming steady state groundwater flow conditions, as modified by the injection of water in Pz CNS. First, the "classical" dual-porosity model (further called the CDPM) was considered, assuming that effective porosity and immobile water porosity are constant values independent of the chalk saturation degree. Second, the dynamic partitioning dual-porosity model (further called the DDPM) was considered. In this case, one does not know exactly the magnitudes of effective porosity and immobile water porosity, the only information being the partitioning coefficient considered as a fitting parameter. Figure 1 shows the chloride breakthrough curve measured in the field together with the best fit obtained (trial-and-error) considering the two approaches considered. Fitted parameters obtained using the CDPM approach are close to those obtained in the saturated zone. This indicates a fast, preferential transit of tracers along partially or fully saturated fissures with physical retardation in the immobile water located in the matrix. With the DDPM approach, the relatively high partitioning coefficient indicates that the effective porosity is small and the immobile water porosity large. The calibrated first order transfer coefficient is smaller than for the CDPM approach because the saturation degree varies spatially. Due to that, there are zones in the unsaturated chalk where the hydraulic conductivity is smaller, which contribute to retarding the tracer.

Tab. 1 - Fitted transport parameters for the variably saturated chalk using the tracer test results.

\begin{tabular}{|c|c|c|c|c|c|c|}
\hline $\begin{array}{l}\text { Injection } \\
\text { well }\end{array}$ & $\begin{array}{l}\text { Experimental } \\
\text { conditions }\end{array}$ & $\begin{array}{c}\text { Modelling } \\
\text { approach }\end{array}$ & $\theta_{m}(-)$ & $\theta_{i m}(-)$ & $\alpha_{L}(\mathrm{~m})$ & $\alpha\left(\mathrm{s}^{-1}\right)$ \\
\hline Pz CS & $\begin{array}{l}\text { Saturated } \\
\text { zone }\end{array}$ & CDPM & 0.004 & 0.05 & 1.0 & $2.0 \times 10^{-7}$ \\
\hline \multirow{4}{*}{ PsCNS } & \multirow{2}{*}{$\begin{array}{l}\text { Intense } \\
\text { recharge }\end{array}$} & CDPM & 0.01 & 0.08 & 1.0 & $2.3 \times 10^{-7}$ \\
\hline & & DDPM & \multicolumn{2}{|c|}{$C_{\text {part }}=0.02$} & 1.0 & $9.0 \times 10^{-8}$ \\
\hline & \multirow{2}{*}{$\begin{array}{c}\text { Natural } \\
\text { infiltration }\end{array}$} & CDPM & 0.10 & 0.15 & 1.0 & $2.3 \times 10^{-7}$ \\
\hline & & DDPM & no tracer & observ & ng the $s$ & ed period \\
\hline
\end{tabular}

The second tracer experiment is more representative of natural downward migration conditions of solute contaminants in the unsaturated chalk. For several reasons, simplifying assumptions were considered. First, the transient character of the recharge was neglected because no data were available on the evolution of water contents in the unsaturated zone. In addition, steady state groundwater flow conditions were assumed, considering the low groundwater levels prevailing at the beginning of the tracer experiments. The objectives of the transport simulations were thus restricted to verify that the strong contrast observed in terms of travel times across the unsaturated chalk could be reproduced and to estimate the effective porosity associated to the chalk in natural infiltration conditions. Using the DDPM approach with the set of hydrodispersive parameters calibrated based on the first tracer experiment or with an effective porosity of $35 \%$ (all the water located in the chalk is mobile) did not give any tracer arrival in the period corresponding to the sampling campaign (2 years). Considering an effective porosity of $10 \%$ and a immobile water porosity of $15 \%$ gave a tracer first arrival in accordance with the observed one (after almost one year). The value obtained for the effective porosity $(10 \%)$ is small to be representative of the matrix porosity. However, if one considers that the travel distance $(+/-10 \mathrm{~m})$ in the model was almost 3 times the actual distance covered by the tracer $(+/-3 \mathrm{~m})$, a rough estimation of $30 \%$ can be assessed for the effective porosity, in better accordance with what is expected for the chalk matrix porosity. From the analysis of these simplified simulations, it can be concluded that in natural infiltration conditions, solute contaminant downward migration occurs across the chalk matrix, as proposed in the conceptual model. 


\section{Conclusions}

Detailed field investigations performed at Bovenistier in the Hesbaye region have provided a very complete dataset for understanding and quantifying water recharge and solute leaching processes across the unsaturated zone overlying the Hesbaye fissured chalk aquifer. In 'normal' infiltration conditions, the recharge is not sufficient to keep the fissure network at saturation. Water infiltrates slowly downward across the matrix and solute transport is influenced by the low hydraulic conductivity and the large porosity of the matrix. As soon as the net infiltration rate is higher than the saturated hydraulic conductivity of the matrix, the excess water is free to infiltrate rapidly through the fissure network. Compared to that, groundwater located in the matrix can be assumed as immobile, contributing only to storage and release of water and solutes, just like in the saturated zone. Based on the results, it can be concluded that the vulnerability of the chalk aquifer to contaminations occurring at the land surface is strongly dependent on the existence of a protective cover. Due to that, the recharge rate at the top of the unsaturated chalk is attenuated and contaminants migrate slowly down through the matrix, enhancing the possibilities for natural attenuation. If the chalk was outcropping, any contaminant present in the infiltrating water would be able to reach very quickly the water table. This conceptual and mathematical model could be used to study the impact of groundwater table fluctuations on the evolution of contaminant concentrations such as nitrates, for the estimation of groundwater quality trends for which this factor has to be considered or as a mathematical translation of recent researches, such as those of Price et al. (2000) or Tokunaga et al. (2000).

\section{References}

Brouyère S., A. Dassargues, R. Therrien, E. Sudicky, Modelling of dual porosity media: comparison of different techniques and evaluation on the impact on plume transport simulations, IAHS Publication $n^{\circ} 265$, ed. F.Stauffer, W.Kinzelbach, K.Kovar \& E.Hoehn. IAHS Press, Wallingford, Oxfordshire, UK, pp. 22-27, 2000.

Brouyère, S., Etude et modélisation du transport et du piégeage des solutés en milieu souterrain variablement saturé (study and modelling of transport and retardation of solutes in variably saturated media), in French, PhD Thesis, University of Liège, Faculty of Applied Sciences, 572p, 2001.

Brouyère S., A. Dassargues, V. Hallet, Migration of contaminants through the unsaturated zone overlying the Hesbaye chalky aquifer in Belgium: a field investigation, J. Contam. Hydrol., in press, 2004.

Durner, W., Hydraulic conductivity estimation for soils with heterogeneous pore structure, Water Resour. Res., 30(2), 211-223, 1994.

Mualem Y., A new model for predicting the hydraulic conductivity of unsaturated porous media, Water Resour. Res., 12(3), 513-522,1976.

Price M., R.G. Low, C.McCann, Mechanisms of water storage and flow in the unsaturated zone of the Chalk aquifer, J. Hydrol., 233, 51-74, 2000.

Ross, P. J., Smetten, R. J., Describing soil hydraulic properties with sums of simple functions, Soil Sci. Soc. Am. J., 57,26-29, 1993.

Tokunaga, K.T., J. Wan, S.R. Sutton, Transient film flow on rough fracture surfaces, Water Resour. Res., 36(7), 1737-1746, 2000.

van Genuchten, M. Th., A closed-form equation for predicting the hydraulic conductivity of unsaturated soils, Soil Sci. Soc. Am. J., 44, 892-898, 1980.

Zurmühl, T., Durner, W., Modeling transient water and solute transport in biporous soil, Water Resour. Res., 32(4), 819-829, 1996. 